\title{
Novel Fluorene Based Host Compounds Designed to Probe Solid-State Fluorescence
}

\author{
Janet L. Scott, ${ }^{*}$ Tomohiko Yamada, ${ }^{1}$ and Koichi Tanaka*,1 \\ Centre for Green Chemistry, Monash University, Clayton, Victoria, 3800, Australia \\ ${ }^{1}$ Department of Applied Chemistry, Faculty of Engineering, Ehime University, Matsuyama, Ehime 790-8577
}

Received February 27, 2004; E-mail: janet.scott@sci.monash.edu.au

Two novel host compounds, 2,7-bis(3-hydroxy-3,3-diphenylprop-1-ynyl)fluorene and 2,7-bis[3,3-(biphenyl-2,2' diyl)-3-hydroxyprop-1-ynyl]fluorene have been synthesized. Many inclusion complexes of these host compounds with common volatile guests show solid-state fluorescence, which is ascribed to the existence of rigid dimers in the crystal structures, allowing excimer formation. Differential intermolecular interactions about the fluorescent moiety result in various colored emissions.

Guest specific fluorescence in solution is frequently used in sensing applications, ${ }^{1}$ but solid-state fluorescence in host:guest complexes is rarer. Host complexes or sensors have been designed to respond selectively to specific organic analytes ${ }^{2}$ (though fluorescence quenching, rather than enhancement, is more frequent in such applications ${ }^{3}$ ). Recently, fluorescence due to toluene inclusion in crystals of disubstituted anthracenes $^{4}$ has been reported and we have previously noted guest specific solid-state fluorescence in crystalline inclusion complexes of 2,7-bis(3-hydroxy-3,3-diphenylprop-1-ynyl)fluoren9-one (1). ${ }^{5}$ Analysis of molecular packing in the crystalline state led to the suggestion that emission was occurring from dimers that formed excimers due to the interactions of close stacked $\pi$ systems. Also of importance was the absence of strong intermolecular interactions (such as hydrogen bonds) to the fluorescent fluorenone core as these would allow radiationless decay to occur in analogous fashion to solution phase hydrogen-bond donors. ${ }^{5 b}$ To test this hypothesis, we have synthesized two new hosts, 2,7-bis(3-hydroxy-3,3-diphenylprop1-ynyl)fluorene (2a) and 2,7-bis[3,3-(biphenyl-2,2'-diyl)-3-hydroxyprop-1-ynyl]fluorene (2b) as shown in Scheme 1, and have screened a range of inclusion complexes for the onset of fluorescence.

Crystallographic investigations, used to probe intermolecular interactions in the solid state, provide a basis for explaining the source of solid state fluorescence and changes in emission $\lambda_{\max }$.

\section{Experimental}

Preparation of 2a. 2,7-Dibromofluorene (2.0 g, $6.2 \mathrm{mmol})$, 1,1-diphenylprop-2-yn-1-ol (2.8 g, $13.6 \mathrm{mmol}), \mathrm{PdCl}_{2}\left(\mathrm{PPh}_{3}\right)_{2}(0.1$ $\mathrm{g}), \mathrm{PPh}_{3}(0.25 \mathrm{~g}), \mathrm{CuI}(0.1 \mathrm{~g})$, and $\mathrm{Et}_{3} \mathrm{~N}(90 \mathrm{~mL})$ were mixed and heated under reflux for $8 \mathrm{~h}$. After filtration of $\mathrm{Et}_{3} \mathrm{~N} \cdot \mathrm{HBr}$, the $\mathrm{Et}_{3} \mathrm{~N}$ solution was evaporated to leave crude $\mathbf{2 a}$. Recrystallization of this from toluene gave pure 2a as colorless prisms (1.88 g, 53\% yield). Mp 186-190 ${ }^{\circ} \mathrm{C}$; IR (Nujol) $3364(\mathrm{OH}) \mathrm{cm}^{-1}$; UV $\left(\mathrm{CHCl}_{3}\right)$ $\lambda_{\max } / \mathrm{nm}(\varepsilon) 219$ (16000), 223 (14200), 297 (37600), 309 (50900), 319 (57600), 325 (52200), 333 (96500); ${ }^{1} \mathrm{HNMR}(300$ $\left.\mathrm{MHz}, \mathrm{CDCl}_{3}\right) \delta 7.28-7.71(\mathrm{~m}, 26 \mathrm{H}, \mathrm{Ar}), 3.88\left(\mathrm{~s}, 2 \mathrm{H}, \mathrm{CH}_{2}\right)$, $2.87(\mathrm{~s}, 2 \mathrm{H}, \mathrm{OH})$. Anal. Calcd for $\mathrm{C}_{43} \mathrm{H}_{30} \mathrm{O}_{2}: \mathrm{C}, 89.25 ; \mathrm{H}$, $5.23 \%$. Found: C, 89.30 ; H, 5.25\%.

Preparation of 2b. 2,7-Dibromofluorene (2.0 g, $6.2 \mathrm{mmol})$, 9ethynyl-9H-fluoren-9-ol (2.8 g, $13.6 \mathrm{mmol}), \mathrm{PdCl}_{2}\left(\mathrm{PPh}_{3}\right)_{2}(0.1 \mathrm{~g})$, $\mathrm{PPh}_{3}(0.25 \mathrm{~g}), \mathrm{CuI}(0.1 \mathrm{~g})$, and $\mathrm{Et}_{3} \mathrm{~N}(90 \mathrm{~mL})$ were mixed and heated under reflux for $8 \mathrm{~h}$. After filtration of $\mathrm{Et}_{3} \mathrm{~N} \cdot \mathrm{HBr}$, the $\mathrm{Et}_{3} \mathrm{~N}$ solution was evaporated to leave crude $\mathbf{2 b}$. Recrystallization of this from toluene gave pure $\mathbf{2 b}$ as colorless needles (1.52 g, $43 \%$ yield). Mp $179-183{ }^{\circ} \mathrm{C}$; IR (Nujol) $3431(\mathrm{OH}) \mathrm{cm}^{-1}$; UV $\left(\mathrm{CHCl}_{3}\right) \lambda_{\max } / \mathrm{nm}(\varepsilon) 240$ (35200), 262 (22100), 298 (39400), 311 (44100), 322 (58800), 337 (87800); ${ }^{1} \mathrm{HNMR}$ (300 MHz, $\left.\mathrm{CDCl}_{3}\right) \delta 7.35-7.81(\mathrm{~m}, 22 \mathrm{H}, \mathrm{Ar}), 3.78\left(\mathrm{~s}, 2 \mathrm{H}, \mathrm{CH}_{2}\right), 2.60(\mathrm{~s}$, $2 \mathrm{H}, \mathrm{OH}$ ). Anal. Calcd for $\mathrm{C}_{43} \mathrm{H}_{26} \mathrm{O}_{2}: \mathrm{C}, 89.87 ; \mathrm{H}, 4.56 \%$. Found: C, $89.65 ; \mathrm{H}, 4.57 \%$.

General Procedure for the Preparation of Inclusion Crystals. Crystallization of host compounds (2a and $\mathbf{2 b}$ ) from a neat solution of various kinds of guest compounds at room tem-

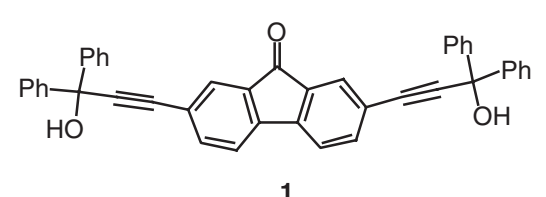

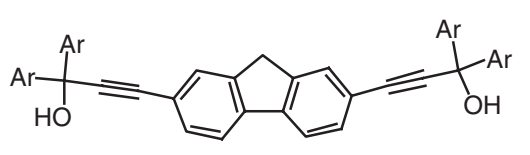

2

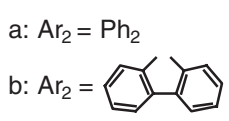

Scheme 1. 
Table 1. Host:Guest Ratio and Fluorescence of Inclusion Complexes of $\mathbf{2 a}$ and $\mathbf{2 b}$

\begin{tabular}{|c|c|c|c|c|}
\hline \multirow{2}{*}{ Guest } & \multicolumn{2}{|c|}{$2 \mathbf{a}$} & \multicolumn{2}{|c|}{$2 b$} \\
\hline & $\mathrm{h}: \mathrm{g}^{\mathrm{a})}$ & Fluorescence & $\mathrm{h}: \mathrm{g}^{\mathrm{a})}$ & Fluorescence \\
\hline Methanol & $1: 1$ & yes (blue) & -b) & - \\
\hline Acetone & $1: 1$ & yes (blue) & $2: 1$ & no \\
\hline Ethyl acetate & - & - & $2: 1$ & no \\
\hline Tetrahydrofuran & - & 一 & $1: 4$ & no \\
\hline Tetrahydropyran & $1: 1$ & yes (blue) & - & - \\
\hline Dioxane & $1: 1$ & yes (yellow) & $1: 1$ & yes (blue) \\
\hline $\mathrm{N}, \mathrm{N}$-Dimethylformamide & $1: 1$ & yes (yellow) & $1: 1$ & yes (blue) \\
\hline$N, N$-Dimethylacetamide & $1: 2$ & yes (yellow) & & \\
\hline$N$-Methyl-2-pyrrolidone & $1: 2$ & yes (yellow) & & \\
\hline Dimethyl sulfoxide & $1: 1$ & yes (blue) & $1: 1$ & no \\
\hline Pyridine & $1: 3$ & yes (blue) & $1: 1$ & yes (blue) \\
\hline Triethylamine & - & - & $1: 1$ & no \\
\hline$N$-Methylpyrrolidine & $1: 2$ & yes (blue) & - & - \\
\hline$N$-Methylpiperidine & $1: 3$ & yes (blue) & - & - \\
\hline
\end{tabular}

a) Host-guest ratios were determined by ${ }^{1} \mathrm{H}$ NMR and TG. b) No complexation occurred.

a

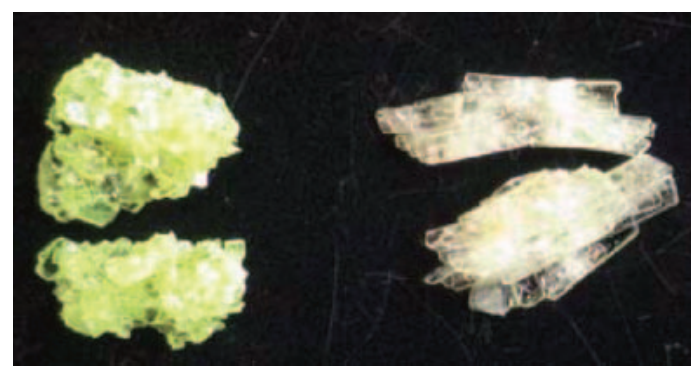

b

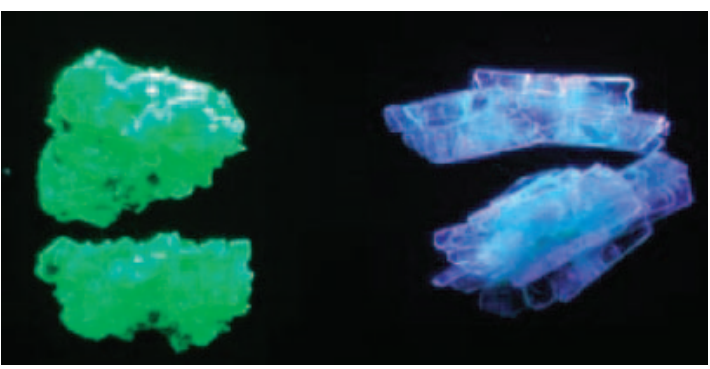

Fig. 1. Photographs of clusters of crystals of the $\mathbf{2 a} \cdot$ DMF complex (left) and $\mathbf{2 a}$ (right) under a) room light-2a.DMF complex is in the form of transparent yellow crystals and 2a is colorless and b) $254 \mathrm{~nm}$ light-2a.DMF complex fluoresces yellow/green and 2a fluoresces blue.

perature yielded inclusion complex crystals, as shown in Table 1. The host-guest ratios were determined by ${ }^{1} \mathrm{H}$ NMR and TG analyses.

Crystal Structure Analysis. Data were collected on an EnrafNonius Kappa CCD diffractometer at $123 \mathrm{~K}$ (223 K for 2a) using graphite monochromated Mo K $\alpha$ radiation $\left(\lambda=0.71073 \AA, 1^{\circ} \varphi\right.$ and $\omega$ scans). Structures were solved by direct methods using the program SHELXS- $97^{6}$ and refined by full matrix least squares refinement on $F^{2}$ using the programs SHELXL-97 ${ }^{7}$ and XSeed. ${ }^{8}$ Non-hydrogen atoms of both host and guest were refined anisotropically and hydrogen atoms, except those involved in hydrogen bonding, inserted in geometrically determined positions with temperature factors fixed at 1.2 times (1.5 for methyl hydrogens) that of the parent atom. Hydroxy group hydrogen atom positions were located from electron density difference maps and both positional parameters and temperature factors were allowed to refine with simple bond length restraints, where necessary. The guest molecules in $\mathbf{2 b} \cdot 0$.5ethyl acetate were disordered and modeled over two positions with $50 \%$ site occupancy. Due to the complex disorder model, guest hydrogen atoms were not included and some residual peaks of the order of 0.5 to $0.75 \mathrm{e} / \AA^{3}$ arise in electron density difference maps in the region of the guest.

\section{Results and Discussion}

Both host compounds $\mathbf{2} \mathbf{a}$ and $\mathbf{2} \mathbf{b}$ form a range of inclusion complexes with differing host:guest ratios, as detailed in

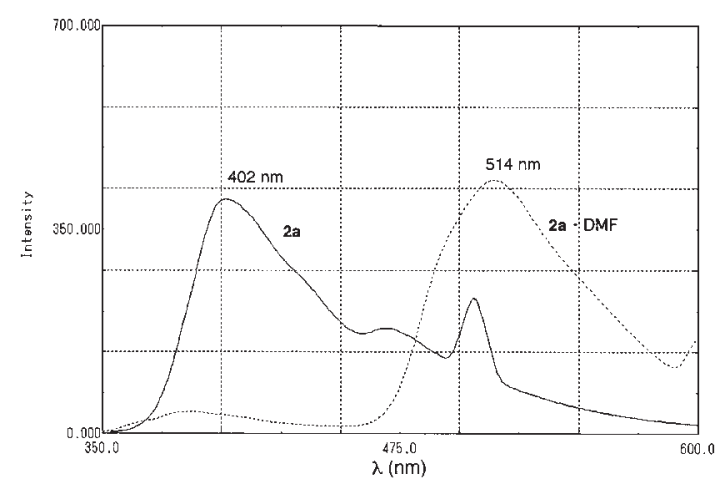

Fig. 2. Emission spectra of $\mathbf{2 a}$ and 2a.DMF complex. Changes in the absorption spectra are far more subtle, with a slight shift to longer wavelength for $\mathbf{2 a}$. DMF complex.

Table 1. Many of the crystalline inclusion complexes luminescence strongly and those of $\mathbf{2 a}$ may emit in different regions of the spectrum, yielding both blue fluorescing complexes (as per the host alone) and bright yellow fluorescent crystals, Fig. 1. This visible color change is reflected in the emission spectra of these complexes, as illustrated in Fig. 2, though there are only small changes in the absorption spectra. The absorption for $\mathbf{2 a} \cdot \mathrm{DMF}$ occurs at slightly longer wavelength than that for $\mathbf{2 a}$ alone, implying very slight differences in ground state 
Table 2. Crystal and Refinement Data

\begin{tabular}{|c|c|c|c|}
\hline & $2 \mathbf{a}$ & 2a.DMF & $2 b \cdot 1 / 2 E t O A c$ \\
\hline Empirical formula & $\mathrm{C}_{43} \mathrm{H}_{30} \mathrm{O}_{2}$ & $\mathrm{C}_{46} \mathrm{H}_{37} \mathrm{NO}_{3}$ & $\mathrm{C}_{45} \mathrm{H}_{30} \mathrm{O}_{3}$ \\
\hline$M_{\mathrm{r}}$ & 578.67 & 651.77 & 618.69 \\
\hline Crystal system & triclinic & triclinic & monoclinic \\
\hline Space group & $P \overline{1}$ & $P \overline{1}$ & $P 2_{1} / c$ \\
\hline$a / \AA$ & $8.6836(2)$ & $9.1413(2)$ & $14.0992(4)$ \\
\hline$b / \AA$ & $11.0594(2)$ & $13.6749(4)$ & $22.7154(6)$ \\
\hline$c / \AA$ & $17.6241(4)$ & $14.9685(4)$ & $10.1453(3)$ \\
\hline$\alpha /^{\circ}$ & $77.849(1)$ & $78.263(2)$ & 90 \\
\hline$\beta /^{\circ}$ & $80.218(1)$ & $81.794(2)$ & $91.328(1)$ \\
\hline$\gamma /{ }^{\circ}$ & $70.533(1)$ & $70.983(1)$ & 90 \\
\hline$V / \AA^{3}$ & $1550.87(6)$ & $1726.13(8)$ & $3248.4(2)$ \\
\hline Z & 2 & 2 & 4 \\
\hline$D_{\text {calcd }} / \mathrm{g} \mathrm{cm}^{-3}$ & 1.239 & 1.254 & 1.265 \\
\hline$\mu / \mathrm{mm}^{-1}$ & 0.075 & 0.078 & 0.078 \\
\hline Refl. unique & 7434 & 8030 & 6809 \\
\hline Refl. $I>2 \sigma(I)$ & 4095 & 4851 & 3434 \\
\hline$R_{1}, w R_{2}[I>2 \sigma(I)]$ & $0.0617,0.1471$ & $0.0516,0.1000$ & $0.0677,0.1470$ \\
\hline$R_{1}, w R_{2}$ [all data] & $0.1310,0.1764$ & $0.1111,0.1178$ & $0.1622,0.1805$ \\
\hline GoF on $F^{2}$ & 1.051 & 1.024 & 1.032 \\
\hline Restraints/parameters & $2 / 414$ & $0 / 455$ & $2 / 459$ \\
\hline
\end{tabular}

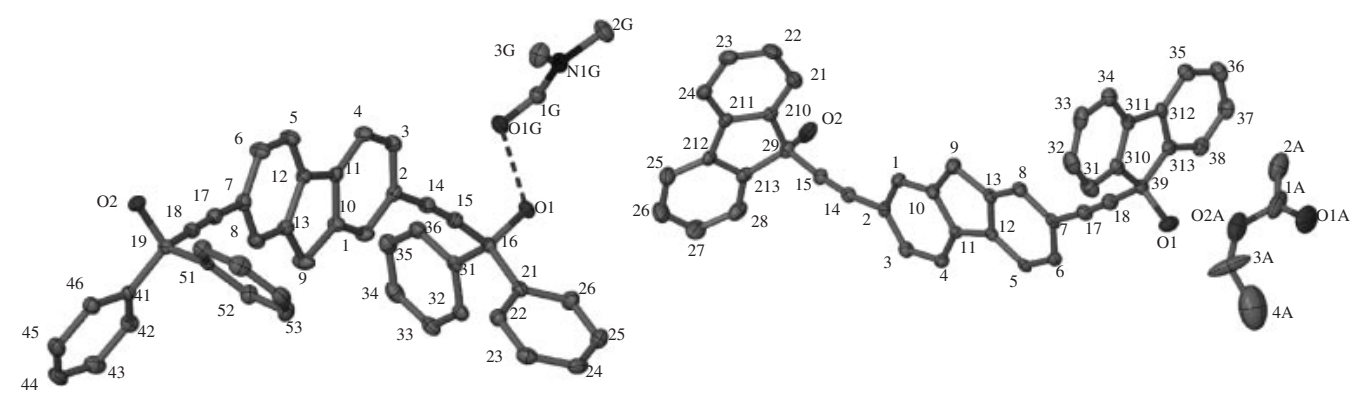

Fig. 3. Molecular numbering for 2a.DMF (left) and $\mathbf{2 b} \cdot 1 / 2$ EtOAc (right) with ellipsoids at the $50 \%$ probability level. Molecular numbering for $\mathbf{2 a}$ alone reflects that of the inclusion complex. Atoms of the ethyl acetate guest are modeled with s.o.f. $=50 \%$.

interactions.

Crystal structure analyses of $\mathbf{2 a}$ alone, the 1:1 inclusion complex of 2a with DMF and the 2:1 inclusion complex of 2b with ethyl acetate were undertaken with the goal of examining intra and intermolecular interactions in the solid state.

Crystal and refinement data are presented in Table 2 and molecular numbering is illustrated in Fig. 3. Both 2a alone and its inclusion complex with DMF crystallize in the space group $P \overline{1}$ with one complete host molecule in the asymmetric unit and $Z=2$. Host molecules in guest free $\mathbf{2 a}$ (blue fluorescence, $\lambda_{\max } 402 \mathrm{~nm}$ ) stack in pairs with close $\pi \cdots \pi$ contacts between the fluorene cores and hydrogen bonds to adjacent molecules, as depicted in Fig. 4a.

In the inclusion complex with DMF, the carbonyl oxygen of the guest molecules acts as a double H-bond acceptor and the dimer is composed of a pair of host molecules with the planar fluorene cores in parallel close contact with one another, as depicted in Fig. 5. The fluorene core is assumed, by analogy with fluorene itself, to be the source of emission ${ }^{9}$ and thus close attention was paid to orientation, intermolecular distances and, particularly, close contacts that would indicate intermolecular interactions. Both fluorescent crystals exhibit dimers with par- allel fluorene aromatic systems in close, $\pi$-stacked contact facilitating the formation of van der Waals dimers and/or excimers in the solid state analogous to those postulated in the gas phase ${ }^{10,11}$ and similar to excimer emission in crystals of pyrene $^{12}$ and perulene. $^{13}$

Subtle differences in interplanar fluorene distances occur in the two crystals and the orientation and registration of these groups also differ slightly, as illustrated in Figs. $4 \mathrm{~b}$ and $5 \mathrm{~b}$. In contrast to the solid-state structure of fluorene itself, where the molecule is distinctly non planar, ${ }^{14}$ the fluorene cores in both structures do not deviate significantly from planarity, yet the fluorene-bis(alkenyl) moiety shows distinct "bowing" in the DMF complex with $\angle \mathrm{C} 19-$ centroid(C11/C13)-C16 = $168^{\circ}$, while it is almost planar $\left(177^{\circ}\right)$ in $\mathbf{2 a}$. Remarkably, this distortion serves to bring the fluorene moieties into closer contact with each other. The calculations of Minn et al. would imply a significant effect on configuration energy and hence on any emissions. ${ }^{9 b}$ Additionally, in $\mathbf{2 a}$ alone, a pair of directed $\mathrm{CH} \cdots \pi$ interactions occur between the hydrogen atoms of $\mathrm{C} 9$ (fluorene methylene group) and the terminal aromatic rings of an adjacent host, as illustrated in Fig. 4c. These rather subtle but concerted interactions would serve to alter the energy of 
$\mathbf{a}$

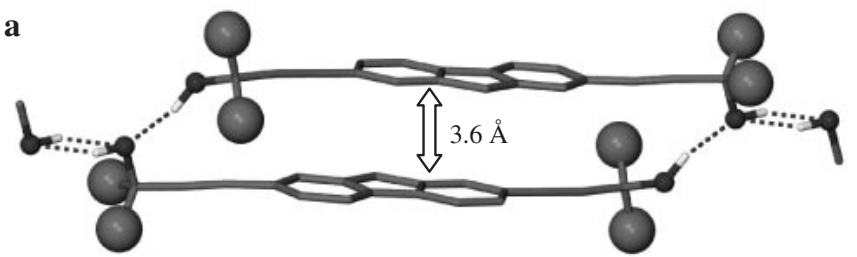

b

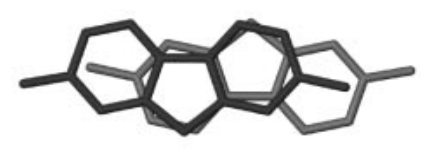

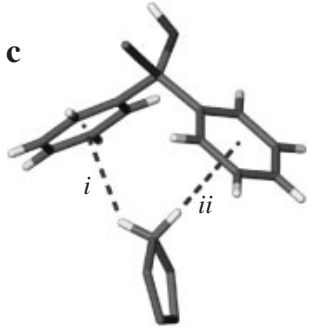

Fig. 4. a) Pairs of 2a stacked with close $\pi \cdots \pi$ contacts between parallel fluorene cores, held together by a hydrogen bond; O2H2O $\cdots \mathrm{O} 1(2-x, 2-y,-z), \mathrm{H}-$ bond geometry: $d \mathrm{O}-\mathrm{H}$ 0.980(2) $\AA, d \mathrm{H} \cdots \mathrm{O} 1.95(2) \AA, d \mathrm{O} \cdots \mathrm{O} 2.899(2) \AA, \angle \mathrm{OHO} 163(4)^{\circ}$; the other forming an $\mathrm{H}$-bond dimer with a neighboring molecule; $\mathrm{O} 1-\mathrm{H} 1 \mathrm{O} \cdots \mathrm{O} 1(3-x, 3-y,-z-1), \mathrm{H}-$ bond geometry: $d$ O-H $0.980(2) \AA, d \mathrm{H} \cdots \mathrm{O} 1.93(3) \AA, d \mathrm{O} \cdots \mathrm{O} 2.793(3) \AA, \angle \mathrm{OHO} 146(4)^{\circ}$ (terminal phenyl rings are replaced by large diameter spheres for clarity). b) Central fluorene cores of one pair showing imperfect registration. c) $\mathrm{C}-\mathrm{H} \ldots \pi$ interactions of the fluorene methylene

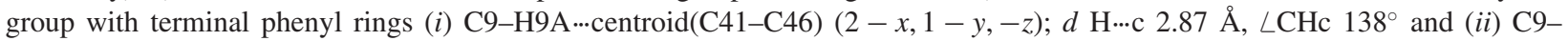

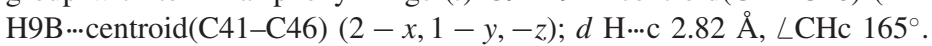

a

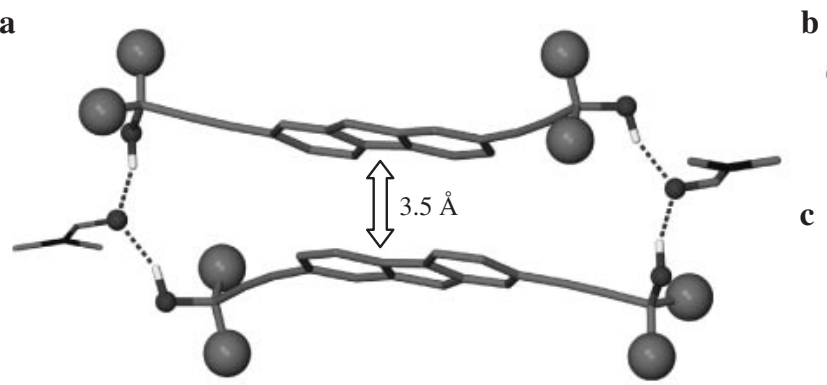

b

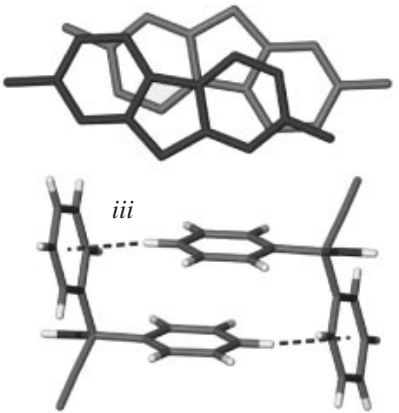

d

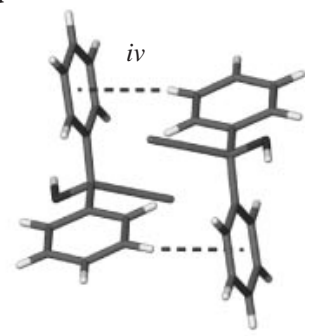

Fig. 5. a) Pairs of $\mathbf{2 a}$ held in close $\pi \ldots \pi$ contact by $\mathrm{OH} \cdots \mathrm{O} \cdots \mathrm{HO}$ hydrogen bonds to the DMF guest molecules. O1-H1O $\ldots$ O1G, Hbond geometry: $d$ O-H $0.98 \AA, d$ H... $1.83 \AA, d$ O $\cdots \mathrm{O}$ 2.756(2) $\AA$, $\angle \mathrm{OHO} 157^{\circ}$; O2-H2O $\cdots \mathrm{O} 1 \mathrm{G}, \mathrm{H}-$ bond geometry: $d$ O-H 0.98 $\AA, d \mathrm{H}$... O $1.80 \AA, d \mathrm{O} \ldots \mathrm{O} 2.743(2) \AA ̊ ., \angle \mathrm{OHO} 160^{\circ}$ (terminal phenyl rings are replaced by large diameter spheres for clarity). b) Central fluorene cores of one pair showing imperfect registration. c) Symmetrical $\mathrm{C}-\mathrm{H} \cdots \pi$ interactions of the terminal phenyl

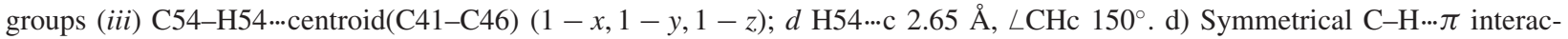
tions of the terminal phenyl groups (iv) $\mathrm{C} 23-\mathrm{H} 23 \cdots$ centroid(C31-C36) $(3-x, 2-y,-z) ; d \mathrm{H} \cdots$ centroid $2.89 \AA, \angle \mathrm{CH}$ cent $161^{\circ}$.

a

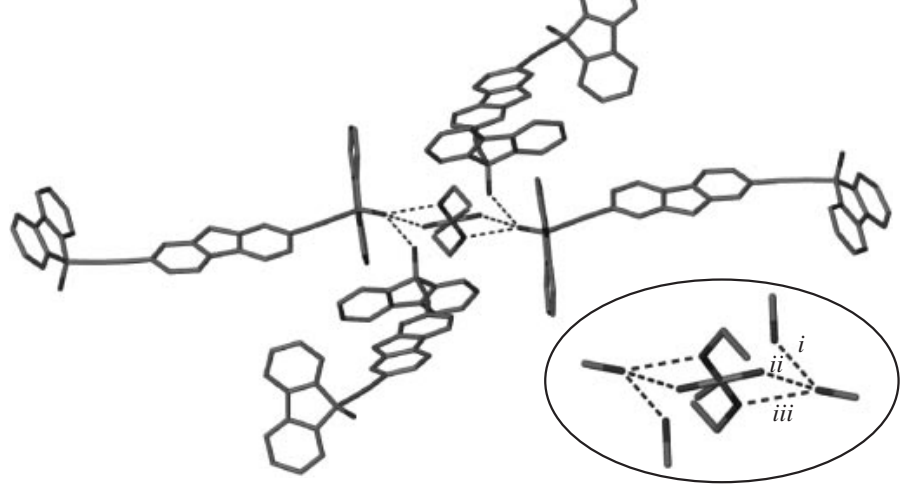

b

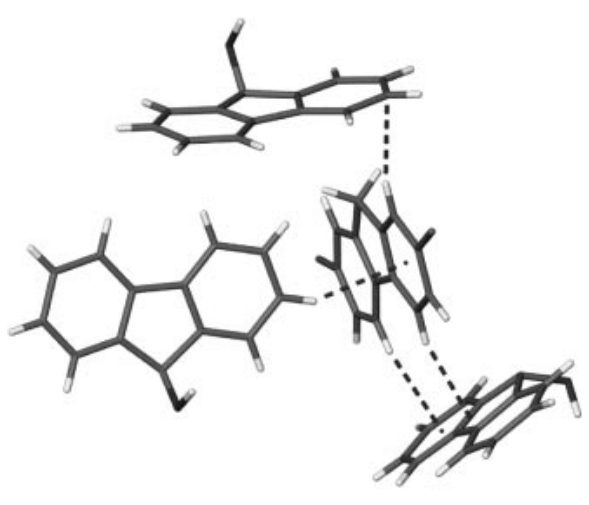

Fig. 6. a) Tetrad of $\mathbf{2 b}$ formed by hosts hydrogen bonded to the disordered guest ethyl acetate located at $0,1 / 2,0$. Unique hydrogen

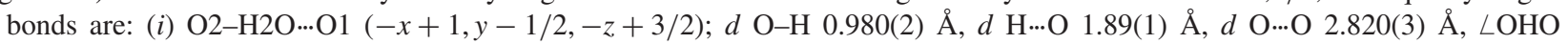

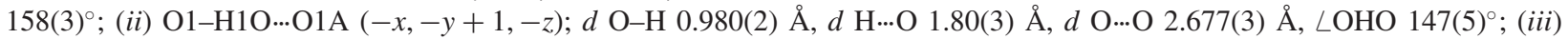

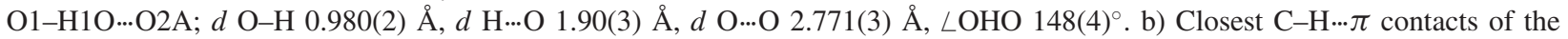
fluorene core.

electronic transitions and hence the emission maxima.

Host $\mathbf{2 b}$ ethyl acetate solvate crystallizes in the space group $P 2_{1} / c$ with a disordered ethyl acetate molecule situated with carbonyl carbon atom on the Wyckoff position $0,1 / 2,0$.
Hydrogen bonded tetrads are generated as illustrated in Fig. 6. More importantly, the central fluorene core does not $\pi$ stack and instead forms part of an extensive set of $\mathrm{CH} \cdots \pi$ edge/face interactions. 
Thus, dimers with $\pi \cdots \pi$ interactions between the fluorene cores occur in both fluorescent crystals of $\mathbf{2 a}$, while these are absent in the non-fluorescing complex $\mathbf{2 b} \cdot 1 / 2$ ethyl acetate. The differences in fluorescence maxima (and hence luminescence color) in crystals of non-complexed and complexed 2a are ascribed to subtle differences in $\pi \cdots \pi$ stacking distances and weak $\mathrm{CH} \cdots \pi$ interactions. These interactions are apparently too weak (long range) to effect radiationless decay as has been noted previously in hydrogen bonded complexes, ${ }^{5}$ but do affect the energy of transitions in the fluorescent moiety of these host molecules.

\section{References}

1 Cation sensing review: a) B. Valeur and I. Leray, Coord. Chem. Rev., 205, 3 (2000). Recent examples: b) W.-L. Wong, K.-H. Huang, P.-F. Teng, C.-S. Lee, and H.-L. Kwong, Chem. Commun., 2004, 384. c) T. Kawase, K. Tanaka, Y. Seirai, N. Shiono, and M. Oda, Angew. Chem., Int. Ed., 42, 5597 (2003). d) A. Prasanna de Silva, G. D. McClean, and S. Pagliari, Chem. Commun., 2003, 2010. e) K. J. Wallace, J. W. Belcher, D. R. Turner, K. F. Syed, and J. W. Steed, J. Am. Chem. Soc., 125, 9699 (2003). f) Y. Kubo, M. Yamamoto, M. Ikeda, M. Takeuchi, S. Shinkai, S. Yamaguchi, and K. Tamao, Angew. Chem., Int. Ed., 42, 2036 (2003).
2 Recent examples: a) F. P. Cossio, A. Arrieta, V. L. Cebolla, L. Membrado, J. Vela, R. Garriga, and M. P. Domingo, Org. Lett., 2, 2311 (2000). b) M. Narita, F. Hamada, I. Suzuki, and T. Osa, J. Chem. Soc., Perkin Trans. 2, 1998, 2751.

3 For example: Y. Takenaka, M. Higashi, and N. Yoshida, J. Chem. Soc., Perkin Trans. 2, 2002, 615.

4 Z. Fei, N. Kocher, C. J. Mohrschladt, H. Ihmels, and D. Stalke, Angew. Chem., Int. Ed., 42, 738 (2003).

5 a) K. Tanaka, M. Asami, and J. L. Scott, J. Chem. Res., Synop., 2003, 483. b) J. L. Scott, T. Yamada, and K. Tanaka, New J. Chem., 28, 447 (2004).

6 G. M. Sheldrick, "SHELXS-97," University of Gottingen (1997).

7 G. M. Sheldrick, "SHELXL-97," University of Gottingen (1997).

8 L. J. Barbour, J. Supramol. Chem., 1, 189 (2001).

9 a) D. L. Horrocks and W. G. Brown, Chem. Phys. Lett., 5, 117 (1970). b) F. L. Minn, J. P. Pinion, and N. Filipescu, J. Phys. Chem., 75, 3445 (1983).

10 a) H. Saigusa and M. Itoh, J. Phys. Chem., 89, 5486 (1985).

b) H. Saigusa and E. C. Lim, J. Phys. Chem., 95, 1194 (1995).

11 H. Saigusa and E. C. Lim, J. Phys. Chem., 95, 2364 (1991).

12 B. Stevens, Spectrochim. Acta, 18, 439 (1962).

13 J. Tanaka, Bull. Chem. Soc. Jpn., 36, 1237 (1963).

14 R. E. Gerkin, A. P. Lunsstedt, and W. J. Reppart, Acta Crystallogr., C40, 1892 (1984). 